\title{
Evaluation of sleep quality and anxiety in Italian pediatric healthcare workers during the first wave of COVID-19 pandemic
}

\author{
Paola Di Filippo ${ }^{1 *} \mathbb{D}$, Marina Attanasi ${ }^{1}$, Giulia Dodi ${ }^{1}$, Annamaria Porreca ${ }^{2}$, Massimiliano Raso ${ }^{1}$, \\ Sabrina Di Pillo ${ }^{1}$ and Francesco Chiarelli ${ }^{1,3}$
}

\begin{abstract}
Objective: The aim of this study was to evaluate sleep quality and psychological effects on pediatric healthcare workers during the first wave of COVID-19 epidemic in Italy and to evaluate differences between primary and secondary care operators. Pediatric healthcare workers were involved in an online survey to assess sleep quality, stress and anxiety level, self-efficacy and social support in Italian pediatric healthcare workers during COVID-19 pandemic.

Results: We found that $67.4 \%$ of our sample suffered from sleep disturbance and $19.4 \%$ of subjects suffered from anxiety. Lower values of anxiety and social support were found in primary care staff compared to secondary care one. The associations between healthcare professional figures (being primary or secondary care operators) and mental health outcomes were not statistically significant. However, sex, age and having a SARS-CoV-2 infected relative/friend had an independent effect on mental health outcomes. It is crucial to provide social and psychological support to pediatric healthcare workers. A tailored psychological screening would be desirable for female healthcare workers and for those who have a SARS-CoV-2 infected relative/friend.
\end{abstract}

Keywords: Insomnia, Pediatric staff, PSQI, Stress, Anxiety, Zung index, Social support, Self-efficacy, COVID-19, Italy, Female sex

\section{Introduction}

The outbreak of coronavirus disease 2019 (COVID19) caused by SARS-CoV-2 infection in Wuhan City in China, spread quickly around the world [1]. The mental impact on population was huge promoting the development of psychological distress and sleep disturbances [2, 3]. Healthcare workers (HWs) were identified as a population at risk for these psychological issues. They faced enormous pressure, caused by the high infection risk, the fear of spreading the infection to their colleagues and their families, the isolation, the verwork, the difficult

\footnotetext{
*Correspondence: difilippopaola@libero.it; paolina__@hotmail.it

1 Department of Pediatrics, University of Chieti, Via dei Vestini 5, 66100 Chieti, Italy

Full list of author information is available at the end of the article
}

patients management and the insufficient personal protective equipment (PPE) $[4,5]$. The mental health of adult healthcare staff received widespread attention [6]. However, Chen et al. [7] found that the prevalence of depression and anxiety was significant also among pediatric medical staff.

The aim of this study was to evaluate sleep quality and psychological effects on pediatric HWs during the first wave of COVID-19 pandemic in Italy and to assess differences between pediatric primary and secondary care.

\section{Main text \\ Methods}

This cross-sectional study was performed using an online self-administered questionnaire survey. We created the survey using Google form platform and we

(c) The Author(s) 2021. This article is licensed under a Creative Commons Attribution 4.0 International License, which permits use, sharing, adaptation, distribution and reproduction in any medium or format, as long as you give appropriate credit to the original author(s) and the source, provide a link to the Creative Commons licence, and indicate if changes were made. The images or other third party material in this article are included in the article's Creative Commons licence, unless indicated otherwise in a credit line to the material. If material is not included in the article's Creative Commons licence and your intended use is not permitted by statutory regulation or exceeds the permitted use, you will need to obtain permission directly from the copyright holder. To view a copy of this licence, visit http://creativeco mmons.org/licenses/by/4.0/. The Creative Commons Public Domain Dedication waiver (http://creativecommons.org/publicdomain/ zero/1.0/) applies to the data made available in this article, unless otherwise stated in a credit line to the data. 
distributed the link obtained by Whatsapp and Facebook. Each answer was recorded anonymously without the possibility to identify the participants.

The questionnaire (Additional file 1) included 94 questions. It was developed through item generation/ reduction as recommended in the guidelines of clinicians' self-administered surveys [8].

Data were collected from May 15th to May 22nd 2020. We identified 450 pediatric HWs, mostly by sending the link to local chat groups.

Pediatric primary care staff included family pediatricians; in Italy the "family pediatrician" is a medical professional who guarantees continuous healthcare assistance along child growth and development. Pediatric secondary care staff included pediatricians, residents and nurses working in some pediatric wards.

Online informed consent was provided by all participants prior to their enrollment and they voluntarily filled out the forms and completed the assessment scales. Choosing a priori the option to not register the incomplete questionnaires in Google Form, only complete questionnaires were included in the statistical analysis.

The questionnaire was composed of several sections (Additional file 1):

a) Questions 1-14, aimed to define participants' sociodemographic characteristics and their expertise in the clinical management of COVID-19 patients; we defined as "clinical management" both medical examination and telephone conversation (telemedicine);

b) Questions 15-32 explored participants' sleep quality by using Pittsburgh Sleep Quality Index (PSQI) [9], a tool validated for Italian population [10];

c) Questions 33-62 evaluated anxiety after traumatic events by using Stanford Acute Stress Reaction Index (SASR) [11];

d) Questions 63-72 measured anxiety levels by using Zung Self-Rating Anxiety Score (Zung index) [12];

e) Questions 73-82 assessed participants' feelings of self-efficacy by using General Self-Efficacy Scale (GSES). Self-efficacy is an important factor to achieve recovery from a stressful event $[13,14]$; higher scores indicate higher self-efficac $[15,16]$;

f) Questions 83-94 measured participants' social support by using Multidimensional Scale of Perceived Social Support (PSS), a research tool measuring perceptions of support from Family, Friends and a Significant Other [17]. Higher score indicating greater perceived social support [18].

\section{Statistical analysis}

Data were presented as median and range for continuous variables and counts and percentages for categorical variables. Shapiro Wilk test was used to check for a normal distribution.

Mann Whitney $U$ test for numerical variables and Pearson's Chi-squared test for categorical data were used to compare survey's answers in Primary Care staff and Secondary Care staff. Post-hoc analysis by Chi-squared residuals was performed according to Beasley and Schumacker [19]. Holm-Bonferroni was used as post-hoc test. Pearson's correlation was used to evaluate the relationship among the study scores (PSQI, SASR, Zung index, GSES, PSS).

A multivariable linear model analysis was fitted to explore the association between healthcare professional figures (being primary or secondary care operators) and mental health outcomes (PSQI, SASR, SAS, GSES, PSS) adjusting for potential confounding factors. Confounders were selected from literature first [20], and were subsequently tested for their association with both determinant and the outcomes, or a change of unadjusted effect estimates of $10 \%$ when added to the univariate model.

The customary 0.05 type I error probability was chosen. All analyses were run in R 3.6.2 [Language and Environment for Statistical Computing. R Core Team, R Foundation for Statistical Computing, Vienna, Austria, 2019; (https://www.R-project.org/)].

\section{Results}

The questionnaire was completed by 175 (response rate $38 \%)$ pediatric HWs [median age 37.0 (55.5-31.0); 76.6\% women]: 58 pediatricians, 55 pediatric residents and 15 pediatric nurses working in pediatric wards and 47 family pediatricians. HW' sociodemographic characteristics and their expertise in the clinical management of COVID-19 patients during pandemic are shown in Table 1.

Median PSQI value resulted 8.0 (5.0-10.0). Specifically $68.6 \%(120 / 175)$ of participants showed a score higher than 5 indicating sleep disturbance, of whom $46.3 \%$ $(81 / 175)$ had a score between 6 and 10 (average sleep quality), 20.0\% (35/175) between 11 and 16 (poor sleep quality) and 2.3\% (4/175) greater than 16 (very poor sleep quality). The median SASR score resulted 63.0 (39.083.0). Median Zung index value resulted 34.0 (30.0-44.0); specifically $19.4 \%$ of participants had a score higher than 50 indicating anxiety. Median GSES score resulted 29.0 (25.0-34.0) and median PSS score was 5.9 (5.3-6.5). Data are shown in Table 2.

We found a positive strong correlation between PSQI and SASR $(\mathrm{r}=0.678 ; p<0.001)$, and between PSQI and Zung index $(\mathrm{r}=0.627 ; p<0.001)$, and between SASR and 
Table 1 Socio-demographic characteristics and occupational data of the respondents

\begin{tabular}{|c|c|c|c|c|}
\hline & All $(\mathrm{N}=175)$ & $\begin{array}{l}\text { Primary care } \\
\text { staff }(N=47)\end{array}$ & $\begin{array}{l}\text { Secondary } \\
\text { care staff } \\
(\mathrm{N}=128)\end{array}$ & $p$ value \\
\hline \multicolumn{5}{|l|}{ Choose your occupation among the following options? } \\
\hline Hospital pediatrician & $58(33.1)$ & & & \\
\hline Pediatric Resident & $55(31.4)$ & & & \\
\hline Pediatric Nurse & $15(8.6)$ & & & \\
\hline Family pediatrician & $47(28.9)$ & & & \\
\hline \multirow[t]{2}{*}{ What is your age? } & & & & $n^{n}<0.001$ \\
\hline & $37.0(55.5-31.0)$ & $\begin{array}{l}60.0(58.0- \\
63.5)\end{array}$ & $33.0(29.0-40.0)$ & \\
\hline Are you a male or a female? & & & & 0.027 \\
\hline Male & $41(23.4)$ & $17(36.2)$ & $24(18.7)$ & \\
\hline Female & $134(76.6)$ & $30(63.8)$ & $104(81.3)$ & \\
\hline Do you have any son or daughter? & & & & $<0.001$ \\
\hline No & $97(55.4)$ & $6(12.8)$ & $91(71,1)$ & \\
\hline Yes & $78(44.6)$ & $41(87.2)$ & $37(28.9)$ & \\
\hline In which macro-area of Italy do you work? & & & & NS \\
\hline North & $19(10.8)$ & $8(17.0)$ & $11(8.6)$ & \\
\hline Center & $141(80.6)$ & $35(74.5)$ & $106(82.8)$ & \\
\hline South & $12(6.9)$ & $4(8.5)$ & $8(6.3)$ & \\
\hline Islands & $3(1.7)$ & $0(0.0)$ & $3(2.3)$ & \\
\hline Do you have any flatmate older than 60 years? & & & & $<0.001$ \\
\hline No & $132(75.4)$ & $24(51.1)$ & $108(84.4)$ & \\
\hline Yes & $43(24.6)$ & $23(48.9)$ & $20(15.6)$ & \\
\hline Do you have any SARS-CoV-2 infected relative/friend? & & & & NS \\
\hline No & $115(65.7)$ & $33(70.2)$ & $82(64.1)$ & \\
\hline Yes & $60(34.3)$ & $14(29.8)$ & $46(35.9)$ & \\
\hline How many COVID-19 patients did you visit or manage by phone? & & & & NS \\
\hline 0 & $76(43.4)$ & $17(36.2)$ & $59(46.1)$ & \\
\hline $1-5$ & $87(49.7)$ & $26(55.3)$ & $61(47.7)$ & \\
\hline $6-15$ & $8(4.6)$ & $4(8.5)$ & $4(3.1)$ & \\
\hline$>15$ & $4(2.3)$ & $0(0.0)$ & $4(3.1)$ & \\
\hline $\begin{array}{l}\text { How many patients with suspected COVID-19 symptoms did you visit or man- } \\
\text { age by phone? }\end{array}$ & & & & NS \\
\hline 0 & $9(5.1)$ & $1(2.1)$ & $8(6.2)$ & \\
\hline$<10$ & $109(61.6)$ & $33(70.2)$ & $76(59.4)$ & \\
\hline $10-30$ & $35(19.8)$ & $12(25.6)$ & $23(18.0)$ & \\
\hline $31-50$ & $11(6.2)$ & $0(0.0)$ & $11(8.6)$ & \\
\hline $51-100$ & $10(5.7)$ & $1(2.1)$ & $9(7.0)$ & \\
\hline$>100$ & $1(0.6)$ & $0(0.0)$ & $1(0.8)$ & \\
\hline $\begin{array}{l}\text { How do you judge the adequacy of personal protective equipment in your } \\
\text { workplace? }\end{array}$ & & & & $<0.001$ \\
\hline Absent & $19(10.9)$ & $17(36.2)$ & $2(1.6)$ & $\begin{array}{l}\text { *Abs-exc } 0.001 \\
{ }^{*} \text { Abs-poor }<0,001 \\
{ }^{*} \text { Abs-suff. }<0,001\end{array}$ \\
\hline Poor & $87(49.7)$ & $0(0.0)$ & $7(5.5)$ & *Poor-suff. $<0,001$ \\
\hline Sufficient & $62(35.4)$ & $29(61.7)$ & $58(45.3)$ & \\
\hline Excellent & $7(4.0)$ & $1(2.1)$ & $61(47.6)$ & \\
\hline Did you perform rhino-pharyngeal swab for SARS-CoV-2? & & & & $<0.001$ \\
\hline No & $79(45.1)$ & $33(70.2)$ & $46(35.9)$ & \\
\hline Yes & $96(54.9)$ & $14(29.8)$ & $82(64.1)$ & \\
\hline
\end{tabular}


Table 1 (continued)

\begin{tabular}{|c|c|c|c|c|}
\hline & All $(\mathrm{N}=175)$ & $\begin{array}{l}\text { Primary care } \\
\text { staff }(N=47)\end{array}$ & $\begin{array}{l}\text { Secondary } \\
\text { care staff } \\
(\mathrm{N}=128)\end{array}$ & $p$ value \\
\hline If Yes, which was the result? & & & & NS \\
\hline Negative & $95(98.9)$ & $14(100)$ & $81(98.8)$ & \\
\hline Positive & $1(1.1)$ & $0(0.0)$ & $1(1.2)$ & \\
\hline Did you perform serologic test for SARS-CoV-2? & & & & 0.006 \\
\hline No & $128(73.1)$ & $42(89.4)$ & $86(67.2)$ & \\
\hline Yes & $47(26.9)$ & $5(10.6)$ & $42(32.8)$ & \\
\hline IfYes, which was the result? & & & & NS \\
\hline Negative $\lg G$ and $\lg M$ & $45(95.8)$ & $4(80.0)$ & $41(97.6)$ & \\
\hline Negative $\lg G$ and positive $\lg M$ & $1(2.1)$ & $1(20.0)$ & $0(0.0)$ & \\
\hline Positive lgG and negative lgM & $1(2.1)$ & $0(0.0)$ & $1(2.4)$ & \\
\hline Positive $\lg G$ and $\lg M$ & $0(0.0)$ & $0(0.0)$ & $0(0.0)$ & \\
\hline
\end{tabular}

Values are absolute numbers (percentages) for categorical data and median (range) for continuous variables. N numbers, NS not significant;

Pediatric primary care staff consisted offamily pediatricians; pediatric secondary care staff consisted of hospital pediatricians, residents in Pediatrics and pediatric nurses; COVID-19 novel coronavirus 19 disease, SARS-CoV-2 Severe Acute Respiratory Syndrome-Coronavirus-2; Ig immunoglobulin

" $p$ value from Mann Whitney $U$ test

$p$ value from Pearson's Chi squared test

Bold formatting to values where the $p$-value is $<0.05$

*adjusted $p$ value from post-hoc test (Bonferroni test) for pairwise Chi-squared test comparisons

Table 2 Evaluation of the psychological effects on the pediatric health-care workers caused by COVID-19 pandemic in Italy

\begin{tabular}{|c|c|c|c|c|}
\hline & All $(N=175)$ & Primary care staff $(\mathrm{N}=47)$ & $\begin{array}{l}\text { Secondary care staff } \\
(\mathrm{N}=128)\end{array}$ & $p$ value \\
\hline PSQI & $8.0(5.0-10.0)$ & $6.0(5.0-9.0)$ & $8.0(5.0-10.0)$ & NS \\
\hline SASR & $63.0(39.0-83.0)$ & $63.0(33.0-89.0)$ & $64.0(41.0-81.2)$ & NS \\
\hline Zung Index & $34.0(30.0-44.0)$ & $31.0(29.0-41.5)$ & $35.0(31.0-44.2)$ & 0.027 \\
\hline GSES & $29.0(25.0-34.0)$ & $30.0(27.0-35.0)$ & $29.0(24.0-33.0)$ & NS \\
\hline PSS & $5.9(5.3-6.5)$ & $5.8(5.2-6.0)$ & $6.0(5.4-6.6)$ & $<0.001$ \\
\hline $\begin{array}{l}\text { *Acute post-traumatic stress } \\
\text { disorder }\end{array}$ & & & & ${ }^{\#} N S$ \\
\hline No & $82(47.0)$ & 23(49.9) & $59(46.1)$ & \\
\hline Yes & $93(53.0)$ & $24(51.1)$ & $69(53.9)$ & \\
\hline
\end{tabular}

Values are absolute numbers (percentages) for categorical variables and median (range) for continuous variables. $N$ numbers, NS not significant; primary care staff consisted of family pediatricians; pediatric secondary care staff consisted of hospital pediatricians, residents in Pediatrics and pediatric nurses

COVID-19 novel coronavirus 19 disease, PSQ/ Pittsburgh Sleep Quality Index, SASR Stanford Acute Stress Reaction Index, GSES General Self-Efficacy Scale, PSS Perceived Social Support; Acute post-traumatic stress disorder is defined according to DSM-IV criteria

$p$ value from Mann Whitney $U$ test for continuous variables

$\# p$ value from Pearson's Chi squared test for categorical variables; bold formatting to values where the $p$-value is $<0.05$

Zung index $(\mathrm{r}=0.648 ; p<0.001)$. Furthermore, a negative weak correlation between SASR and GSES $(r=-0.264$; $p<0.001)$, and between SASR and PSS $(\mathrm{r}=-0.161$; $p=0.033)$ was found. Data are shown in Fig. 1A.

No significant difference was found for the number of managed COVID-19 patients between primary and secondary care staff. However, the provision of PPE, the percentage of subjects who performed the rhino-pharyngeal swabs and the serology for SARS-CoV-2 were significantly different between the two groups (Table 1 ).

No differences were found between primary and secondary care staff for PSQI and SASR [6.0 (5.0-9.0) vs. 8.0 $(5.0-10.0) p=0.09 ; 63.0(33.0-89.0)$ vs. $64.0(41.0-81.2)$ $p=0.73$, respectively). Lower values of anxiety and social support [31.0 (29.0-41-5) vs. $35.0(31.0-44.2) p=0.02$; $5.8(5.2-6.0)$ vs. $6.0(5.4-6.6) p=0.001$ respectively) were 
(A)
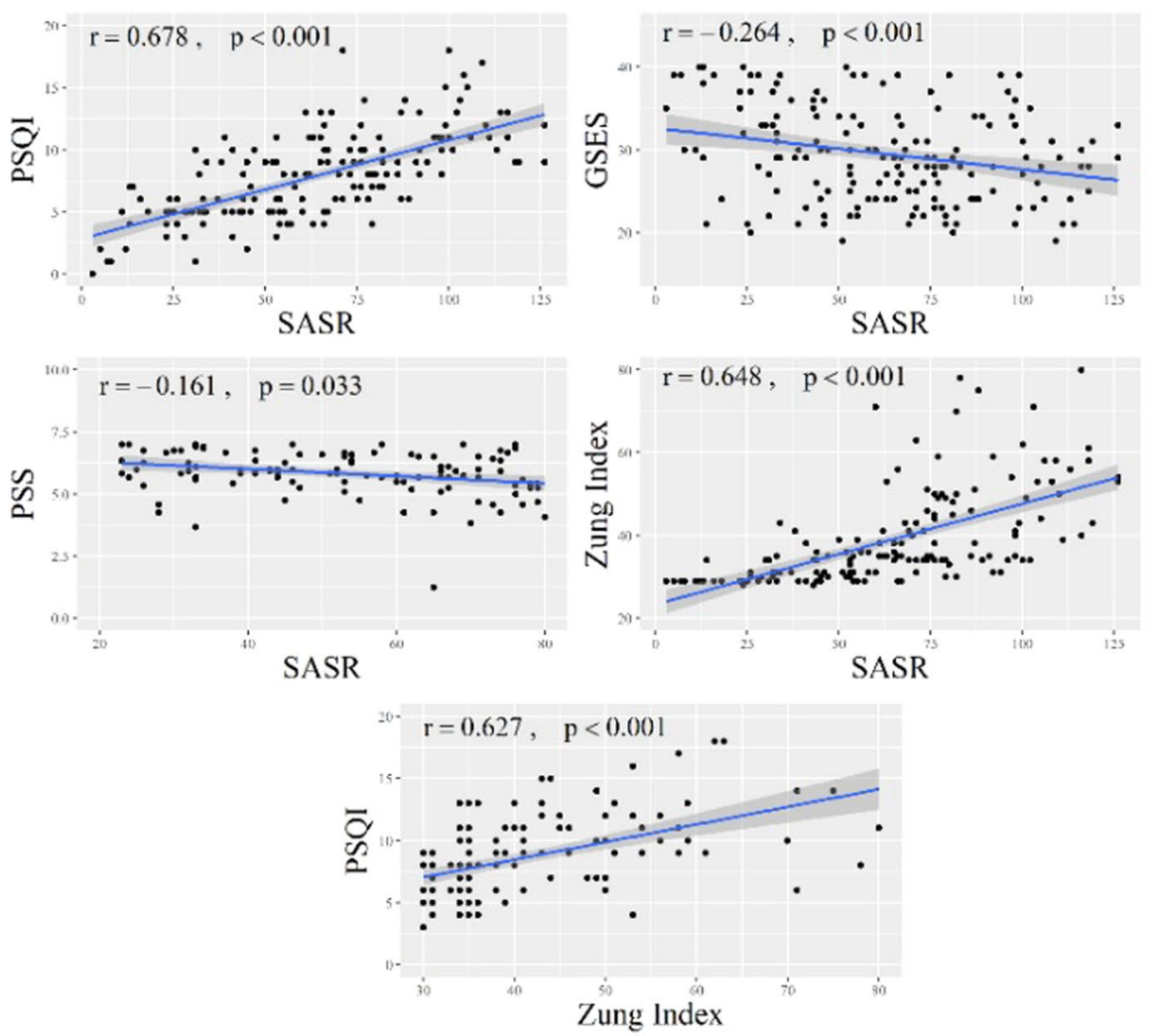

(B)

$$
\text { Zung lndex }
$$

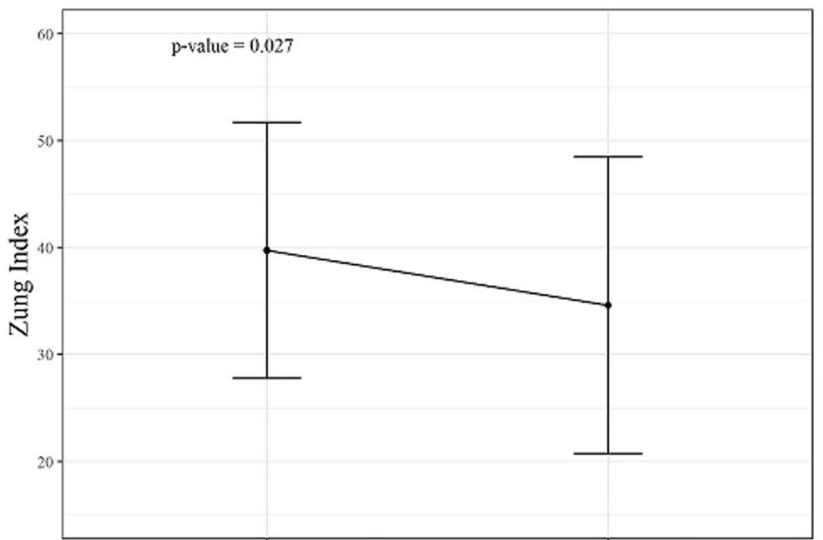

Secondary Care Staff

Primary Care Staff

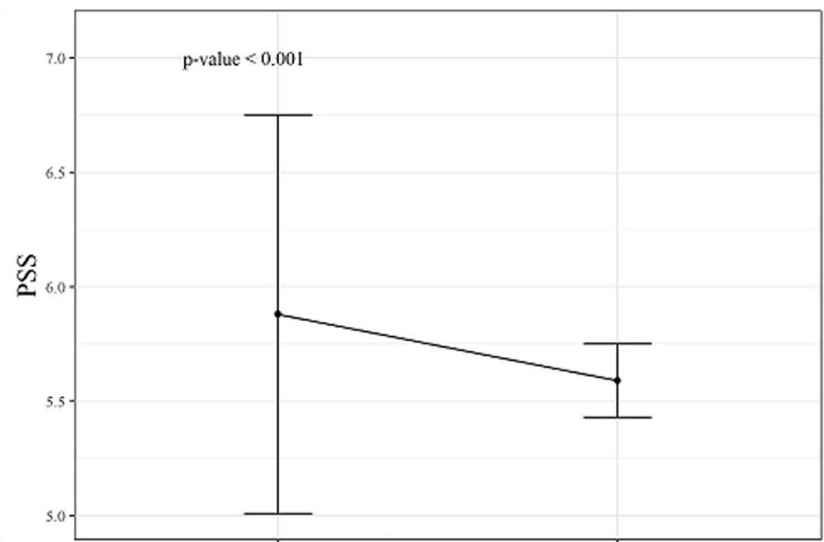

Secondary Care Staff

Primary Care Staff

Group

Fig. 1 A Correlations between the scores used for evaluating COVID-19 pandemic psychological effects on pediatric healthcare workers. PSQI Pittsburgh Sleep Quality Index, SASR Stanford Acute Stress Reaction Index, GSES General Self-Efficacy Scale, PSS Perceived Social Support. $p$ value was from Pearson correlation. B Difference of Anxiety and Social Support between pediatric primary and secondary care staff. PSS Perceived Social Support; Values are expressed as median and range. $p$ value was from Unpaired $t$ test

found in primary care staff compared to secondary care one (Fig. 1B).

The associations between healthcare professional figures (being primary or secondary care operators) and mental health outcomes (PSQI, SASR, Zung index, GSES,
PSS) were not statistically significant even after adjusting for confounders (sex, age, having SARS-CoV-2 infected relative/friend). However, sex had a direct independent effect on PSQI, SASR, Zung index and GSES, age had a direct independent effect on PSS and having at least one 
SARS-CoV-2 infected relative/friend had a direct independent effect on PSQI, SASR and PSS (Additional file 2).

\section{Discussion}

COVID-19 resulted to be less frequent and severe in children compared to adults [21]. Furthermore, closing schools, lockdown measures and the reluctance to attend pediatric consultations (where the infection risk was high) [22] led to a substantial decrease (ranging from 73 to $88 \%$ ) in Pediatric Emergency Department visits compared to the same time period in 2019 and 2018 [23, 24]. All these factors created a condition in pediatric wards completely opposed to adult wards which were characterized by running out of beds in a few days [25].

According to these findings, in our study sample we showed a low exposure and infection rate, detected by rhino-pharyngeal swab and serological test (Table 1) compared to all Italian HWs [26].

During the first wave of COVID-19 outbreak we found that $67.4 \%$ of participants suffered from sleep disturbance (PSQI > 5) with a median PSQI score of 8.0 (5.0-10.0).

Before COVID-19 pandemic in Italian population the poor sleep quality prevalence (measured by PSQI) was already 40.5\% [27] and worsened during lockdown [28]. However, we showed a further increased prevalence of sleep distress in our pediatric staff (67.4\%) compared to Italian population (52.4\% measured by PSQI) [27]. Our PSQI value resulted higher than the value of Chinese pediatric HWs (7.2 \pm 2.62$)$ [29] but lower than Chinese frontline HWs (9.3 \pm 3.8$)$ [30].

Furthermore, we found a correlation between stress/ anxiety and poor sleep quality confirming their negative effect on sleep of the pediatric HWs during COVID-19 pandemic. On one hand, stress and anxiety are considered the main precipitating factors for insomnia [31, 32]. On the other hand, sleep quality is an important factor regulating behaviors and emotions [33] revealing the bidirectional relationship between sleep quality and psychological distress.

We found a SASR value of $63.0(39.0-83.0)$ which was lower than Chinese frontline HWs $(77.6 \pm 29.5)$ [34]. Our pediatric staff showed a median Zung index value of 34.0 (30.0-44.0), which was similar to Chinese pediatric HWs $(34.4 \pm 7.2)$ [29] and lower than Chinese frontline HWs $(55.3 \pm 14.2)$ [34]. Thirty-four participants (19.4\%) suffered from anxiety showing a Zung score value $\geq 50$. Before COVID-19 pandemic the prevalence of anxiety in Italian population was of $10.3 \%$ [35] and increased during the pandemic (21.3\%) [25]. In our study sample the prevalence of anxiety was lower compared to Italian population and to frontline HWs (20.6\%), and similar to second-line HWs (18.1\%) [25]. In a recent meta-analysis with 162.639 participants the prevalence of anxiety was similar between HWs and general population (26.0 and $32.0 \%$ respectively), and the highest value was found in Italy compared to other countries [36].

Furthermore, in our pediatric staff we showed a high social support, which could explain the decrease of stress levels. A recent survey with 2166 subjects showed that HWs with less social support had more psychological consequences [37] maybe for the limited opportunities to express their emotions $[38,39]$.

Regarding the subgroup analysis, primary care staff presented a lower value of anxiety compared to secondary care staff one [31.0 (29.0-41.5) vs. $35.0(31.0-44.2)$ $p=0.027]$.

We showed that being primary or secondary care staff was not a risk factor for a worsening of the mental health outcomes (PSQI, SASR, Zung index, GSES, PSS). Noteworthy, female sex showed an independent effect on PSQI, SASR and Zung index. Our findings are in line with previous studies, showing that female sex was associated with increased perception of events as more negative and uncontrollable than male sex predisposing to anxiety [39] and poor sleep quality [40, 41], as also found among medical staff during COVID-19 pandemic [25, 36, 42].

We also showed that having at least one SARS-CoV-2 infected relative/friend had an independent effect on PSQI and SASR, in line with other studies $[4,43]$. Moreover, age had an independent effect on PSS. In our study the social support was higher in secondary care compared to primary care staff, probably because family pediatricians were older [42] and work alone without any cooperation with other professional figures.

Concluding, during the first wave of pandemic Italian pediatric HWs suffered from psychological disorders, in particular sleep disturbances and anxiety. Our study emphasizes the necessity of supporting pediatric HWs, which is particularly desirable for female HWs and for those who have at least one SARS-CoV-2 infected relative/friend because they seem to be predictors of anxiety and sleep disorders.

However, further observational studies with larger sample are needed to confirm our findings and longitudinal prospective studies are required to define the longterm mental reverberations in pediatric HWs.

\section{Limitations}

Our study is the first Italian survey investigating sleep quality and psychological status in pediatric HWs and evaluating differences between pediatric primary and secondary care operators.

However, there are some limitations to mention. Firstly, it is a self-administered survey and self-selection bias could have led to an overestimation of effect sizes [44]. 
Furthermore, self-report measures could convey a further systematic bias. The overall response rate was relatively low, limiting results generalizability. However, the response rate was similar to other surveys in literature $[45,46]$. Another important limitation is its cross-sectional nature because of the impossibility of assessing the temporal relationship between exposure and outcome. Lastly, although the two groups had a different composition (only medical doctors in primary care staff) and hence not fully comparable, a recent survey with 2166 respondents showed that nurses and medical doctors suffered from equal anxiety symptoms severity [37].

\section{Abbreviations}

SARS-CoV-2: Severe acute respiratory syndrome coronavirus 2; COVID-19: Coronavirus Disease 2019; HWs: Healthcare Workers; PPE: Personal Protective Equipment; PSQI: Pittsburgh Sleep Quality Index; SASR: Stanford Acute Stress Reaction; SAS: Self- Rating Anxiety Score; GSES: General Self-Efficacy Scale.

\section{Supplementary Information}

The online version contains supplementary material available at https://doi. org/10.1186/s13104-021-05621-9.

Additional file 1. Survey administered to our study sample. The questionnaire was composed of six sections: A socio-demographic characterization of respondents and definition of their expertise in the clinical management of COVID-19 patients during the first wave of pandemic; $\mathbf{B}$ evaluation of the participants'sleep quality; $\boldsymbol{C}$ evaluation of anxiety after traumatic events; $\mathbf{D}$ measurement of anxiety levels; E participants' feelings of self-efficacy; $\mathbf{F}$ participants' perceived social support.

Additional file 2. Multivariable Linear Regression Model to evaluate the association between the type of professional figure (pediatric secondary care vs primary care staff) and health mental outcomes.

\section{Acknowledgements}

We thank all physicians and nurses who answered our questions during the overwhelming days of the pandemic. The authors would like to thank the pediatric residents and nurses of the Department of Pediatrics, University of Chieti.

\section{Authors' contributions}

DF conceptualized and distributed the questionnaire, coordinated the study, drafted and critically reviewed the manuscript for important scientific content; MA provided the statistical analysis, created figures and tables and critically reviewed the manuscript for important scientific content and for English language; AP provided the statistical analysis and created figures; GD and MR distributed the questionnaire, collected data and reviewed the manuscript; SDP and FC reviewed critically the manuscript. All authors read and approved the final manuscript.

\section{Funding}

Not applicable.

\section{Availability of data and materials}

The datasets used and analyzed during the current study are available from the corresponding author on reasonable request.

\section{Declarations}

\section{Ethics approval and consent to participate}

According to our Ethic Committee (Comitato Etico per la Ricerca Biomedica delle Province di Chieti e di Pescara e dell'Università degli Studi "G.d'Annunzio" di Chieti e Pescara) [47] policy, no ethics approval was required for a survey. Since we enrolled only competent adults, with no or minimal risks of harm, participants were informed that the survey questions are part of a research study and that answering the questions is voluntary. In fact, the informed individual provided their willingness to participate by choosing to complete the survey [8].

\section{Consent for publication}

Not applicable.

\section{Competing interests}

All authors disclose no personal or financial support or author involvement with organizations with financial interest in the subject.

\section{Author details}

${ }^{1}$ Department of Pediatrics, University of Chieti, Via dei Vestini 5, 66100 Chieti, Italy. ${ }^{2}$ Department of Economic Study, University of Chieti, Chieti, Italy. ${ }^{3}$ Center of Excellence on Aging, "G.D'Annunzio" University Foundation, University of Chieti, Chieti, Italy.

Received: 19 April 2021 Accepted: 15 May 2021

Published online: 02 June 2021

\section{References}

1. Rahman B, Sadraddin E, Porreca A. The basic reproduction number of SARS-CoV-2 in Wuhan is about to die out, how about the rest of the World? Rev Med Virol. 2020;19:e2111.

2. Lazzerini M, Putoto G. COVID-19 in Italy: momentous decisions and many uncertainties. Lancet Glob Heal. 2020:8:641-2.

3. Mazza C, Ricci E, Biondi S, Colasanti M, Ferracuti S, Napoli C, et al. A nationwide survey of psychological distress among Italian people during the COVID-19 pandemic: immediate psychological responses and associated factors. Int J Environ Res Public Health. 2020:17:3165.

4. Spoorthy MS, Pratapa SK, Mahant S. Mental health problems faced by healthcare workers due to the COVID-19 pandemic_-a review. Asian J Psychiatr. 2020;51:102119.

5. Chow KM, Law BMH, Ng MSN, Chan DNS, So WKW, Wong CL, et al. A review of psychological issues among patients and healthcare staff during two major coronavirus disease outbreaks in china: contributory factors and management. Int J Environ Res Public Health. 2020;17:6673. https://doi.org/10.3390/ijerph17186673.

6. Xiang YT, Yang Y, Li W, Zhang L, Zhang Q, Cheung T, et al. Timely mental health care for the 2019 novel coronavirus outbreak is urgently needed. Lancet Psychiatry. 2020;7:228-9.

7. Chen Y, Zhou H, Zhou Y, Zhou F. Prevalence of self-reported depression and anxiety among pediatric medical staff members during the COVID19 outbreak in Guiyang. China Psychiatry Res. 2020;288:113005.

8. Burns KEA, Duffett M, Kho ME, Meade MO, Adhikari NKJ, Sinuff T, et al. A guide for the design and conduct of self-administered surveys of clinicians. CMAJ. 2008;179:245-52.

9. Carpenter JS, Andrykowki AM. Psychometric evaluation of the Pittsburgh Sleep quality index. J Psychosom Res. 1998;45:5-13.

10. Curcio G, Tempesta D, Scarlata S, Marzano C, Moroni F, Rossini PM, et al. Validity of the Italian version of the Pittsburgh sleep quality index (PSQI). Neurol Sci. 2013;34:511-9.

11. Cardena E, Koopman C, Classen C, Waelde LC, Spiegel D. Psycometric properties of the Stanford Acute Stress Reaction Questionnaire (SASRQ): a valid and reliable measure of acute stress. J Trauma Stress. 2000:13:719-34.

12. Zung W. A rating instrument for anxiety disorders. Psychosomatics. 1971;12:371-9.

13. Bandura A. Self-efficacy: toward a unifying theory of behavioral change. Psychol Rev. 1977;84:191-215.

14. DiClemente CC, Carbonari JP, Montgomery RPG, Hughes S. The alcohol abstinence self-efficacy scale. J Stud Alcohol. 1994;55:141-8.

15. Schwarzer R, Jerusalem M. Generalized self-efficacy scale. In: Weinman J, Wright S, Johnston M, editors. Measures in health psychology: a user's Portfolio. Causal and control beliefs. Windsor: NFER-NELSON; 1995. p. $35-7$. 
16. Scholz U, Gutiérrez-Doña B, Sud S, Schwarzer R. Is general self-efficacy a universal construct? Psychometric findings from 25 countries. Eur J Psychol Assess. 2002;18:242-51.

17. Pierce GR, Sarason BR, Sarason I. Integrating Social Support Perspectives: working models, personal relationships and situational factors. 1990 in Duck S (Ed.) with Silver RC. Personal relationships and social support. Newbury Park CA, pp. 173-189

18. Zimet GD, Dahlem NW, Zimet SG, Farley GK. The multidimensional scale of perceived social support. J Pers Assess. 1988;52:30-41.

19. Beasley TM, Schumacher RE. Multiple regression approach to analyzing contingency tables: post hoc and planned comparison procedures. J Exp Educ. 1995;64:79-93.

20. Hossain MM, Tasnim S, Sultana A, Faizah F, Mazumder H, Zou L, et al. Epidemiology of mental health problems in COVID-19: a review Version 1. F1000Res. 2020;9:636. https://doi.org/10.12688/f1000research.24457.1.

21. Sinaei R, Pezeshki S, Parvaresh S, Sinaei R. Why COVID-19 is less frequent and severe in children: a narrative review. World J Pediatr. 2020;25:1-11. https://doi.org/10.1007/s12519-020-00392-y.

22. Enyama D, Chelo D, Njinkui DN, Kouam JM, Djike YF. Impact of the COVID19 pandemic on pediatricians' clinical activity in Cameroon. Arch Pediatr. 2020;27:423-7.

23. Li H, Yu G, Duan H, Fu JFSQ. Changes in children's healthcare visits during COVID-19 pandemic in Hangzhou. China J Pediatr. 2020;224:146-9. https://doi.org/10.1016/j.jpeds.2020.05.013.

24. Lazzerini M, Barbi E, Apicella A, Marchetti F, Cardinale F, Trobia G. Delayed access or provision of care in Italy. Lancet Child Alolesc Health. 2020:4:10-1.

25. Rossi R, Socci V, Pacitti F, Mensi S, Di Marco A, Siracusano A, et al. Mental health outcomes among healthcare workers and the general population during the COVID-19 in Italy. Front Psychol. 2020;11:608986.

26. Istituto Superiore di Sanità ISS. https://www.epicentro.iss.it/coronavirus/ bollettino/Bollettino-sorveglianza-integrata-COVID-19_14-maggio-2020. pdf. Accessed 30 May 2020

27. Cellini N, Canale N, Mioni G, Costa S. Changes in sleep pattern, sense of time and digital media use during COVID-19 lockdown in Italy. J Sleep Res. 2020;15:e13074.

28. Altena E, Baglioni C, Espie CA, Ellis J, Gavriloff D, Holzinger B, et al. Dealing with sleep problems during home confinement due to the COVID-19 outbreak: practical recommendations from a task force of the European CBT-I Academy. J Sleep Res. 2020;29:e13052. https://doi.org/10.1111/jsr. 13052.

29. Wang S, Xie L, Xu Y, Yu S, Yao B, Xiang D. Sleep disturbances among medical workers during the outbreak of COVID-2019. Occup Med (Lond). 2020;70:364-9. https://doi.org/10.1093/occmed/kqaa074.

30. Qi J, Xu J, Li B, Huang JS, Yang Y, Zhang ZT, et al. The evaluation of sleep disturbances for Chinese frontline medical workers under the outbreak of COVID-19. Sleep Med. 2020:72:1-4.

31. Sateia MJ. International classification of sleep disorders-third edition: highlights and modifications. Chest. 2014;146:1387-94.

32. Altena E, Micoulaud-Franchi JA, Geoffroy PA, Sanz-Arigita E, Bioulac S, Philip P. The bidirectional relation between emotional reactivity and sleep: from disruption to recovery. Behav Neurosci. 2016;130:336-50.

33. Simon EB, Oren N, Sharon H, Kirschner A, Goldway N, Okon-Singer H, et al. Losing neutrality: the neural basis of impaired emotional control without sleep. J Neurosci. 2015;35:13194-205.
34. Xiao H, Zhang Y, Kong D, Li S, Yang N. The Effects of social support on sleep quality of medical staff treating patients with coronavirus disease 2019 (COVID-19) in January and February 2020 in China. Med Sci Monit. 2020;26:1-8. https://doi.org/10.12659/MSM.923549.

35. Girolamo G, Polidori G, Morosini P, Scarpino V, Reda V, Serra G, et al. Prevalence of common mental disorders in Italy. Soc Psychiatry Psychiatr Epidemiol. 2006;41:853-61. https://doi.org/10.1007/s00127-006-0097-4.

36. Luo M, Guo L, Yu M, Jiang W, Wang $H$. The psychological and mental impact of coronavirus disease 2019 (COVID19) on medical staff and general public - a systematic review and metaanalysis. Psychiatry Res. 2020;291:113190.

37. Htay MNN, Marz RR, AIRifai A, Kamberi F, El-Abasiri RA, Nyamache JM, et al. Immediate impact of COVID-19 on mental health and its associated factors among healthcare workers: a global perspective across 31 coutries. J Glob Health. 2020;10:020381.

38. Brooks SK, Webster RK, Smith LE, Woodland L, Wessely S, Greenberg N, et al. The psychological impact of quarantine and how to reduce it: rapid review of the evidence. Lancet. 2020;395:912-20.

39. Mo Y, Deng L, Zhang L, Lang Q, Liao C, Wang N, et al. Work stress among Chinese nurses to support Wuhan in fighting against COVID-19 epidemic. J Nurs Manag. 2020;28:1002-9.

40. Barrea L, Pugliese G, Framondi L, Di Matteo R, Laudisio D, Savastano S, et al. Does Sars-Cov-2 threaten our dreams? Effect of quarantine on sleep quality and body mass index. J Transl Med. 2020;18:318. https://doi.org/ 10.1186/s12967-020-02465-y.

41. Demartini B, Nisticò V, D’Agostino A, Priori A, Gambini O. Early psychiatric impact of COVID-19 pandemic on the general population and healthcare workers in italy: a preliminary study. Front Psychiatry. 2020;11:561345. https://doi.org/10.3389/fpsyt.2020.561345.

42. Li F, Luo S, Mu W, Li Y, Ye L, Zheng X, et al. Effects of sources of social support and resilience on the mental health of different age groups during the COVID-19 pandemic. BMC Psychiatry. 2021;21:16.

43. Franceschini C, Musetti A, Zenesini C, Palagini L, Scarpelli S, Quattropani $\mathrm{MC}$, et al. Poor sleep quality and its consequences on mental health during the COVID-19 lockdown in Italy. Front Psychol. 2020;11:574475. https://doi.org/10.3389/fpsyg.2020.574475.

44. DesRoches CM, Campbell EG, Rao SR, Donelan K, Ferris TG, Jha A, et al. Electronic health records in ambulatory care-a national survey of physicians. N Engl J Med. 2008;359:50-60. https://doi.org/10.1056/NEJMs a0802005.

45. Aerny-Perreten N, Domínguez-Berjón MF, Esteban-Vasallo MD, GarciaRiolobos C. Participation and factors associated with late or non-response to an online survey in primary care. J Eval Clin Pract. 2015;21:688-93.

46. Listyowardojo TA, Nap RE, Johnson A. Demographic differences between health care workers who did or did not respond to a safety and organizational culture survey. BMC Res Notes. 2011;4:328.

47. Comitato Etico per la Ricerca Biomedica delle Province di Chieti e di Pescara e dell'Università degli Studi "G. d'Annunzio" di Chieti e Pescara. http:// comitatoetico.unich.it/allegati_2018/regolamento_funzionamento.pdf. Accessed 14 May 2020.

\section{Publisher's Note}

Springer Nature remains neutral with regard to jurisdictional claims in published maps and institutional affiliations. 